\title{
El microbioma y el viroma humano: una nueva perspectiva dentro de las patologías bucales y sistémicas. Revisión bibliográfica
}

\section{The microbioma and the human viroma: a new perspective within the oral and systemic pathologies. Bibliographic review}

\begin{abstract}
Resumen
La presente investigación se basa en una revisión bibliográfica que tuvo como objetivo describir las características del microbioma y viroma, y cómo influyen las variaciones de los mismos en el proceso de salud y enfermedad en la cavidad oral del ser humano, para ello se emplearon las bibliotecas virtuales BVS y PubMed, así como Scholar google y LILACS, se utilizaron como palabras para la búsqueda: microbioma, viroma y cavidad bucal. Se seleccionaron un total de 58 artículos tanto en inglés como español que cumplieron como criterio de inclusión tener máximo 5 años de haberse publicado al momento de la búsqueda, se incluyeron estudios observacionales, descriptivos y explicativos, con valor epidemiológico, biológico y metodológico. Se concluye que existe evidencia científica publicada que respalda que tanto el microbioma como el viroma juegan un papel importante en los procesos de salud y enfermedad, permitiendo analizar las disbiosis, tanto a nivel bucal como sistémico. Se requieren más estudios para conocer a profundidad esta compleja relación y su repercusión en el estado de salud de los individuos.
\end{abstract}

Palabras clave: Microbioma; Microbiota; Cavidad bucal; Viroma (fuente: DeCS BIREME)

\begin{abstract}
The present research is based on a bibliographic review that aimed to describe the characteristics of the microbiome and virome, and how their variations influence the health and disease process in the oral cavity of humans, for which the VHL virtual libraries and PubMed, as well as Scholar google and LILACS, were used as search words: microbiome, virome and oral cavity. A total of 58 articles were selected, both in English and Spanish, which fulfilled the inclusion criteria of having a maximum of 5 years of having been published at the time of the search. Observational, descriptive and explanatory studies were included, with value epidemiological, biological and methodological. It is concluded that there is published scientific evidence that supports that both the microbiome and the virome play an important role in health and disease processes, allowing
\end{abstract}

\section{Artículo de Revisión}

Omaira Fernández ${ }^{1, a, b}$, Patricia Rodríguez ${ }^{1, a}$, Miguel

Flores-Asenso 1,a , Davide Mobili-Rocaro 1,2,a , María

Cristina Aguilera $1, \mathrm{~b}, \mathrm{c}$

${ }^{1}$ Universidad de Carabobo, Facultad de Odontología, Estado Carabobo, Venezuela.

2 Universidad Arturo Michelena, Estado Carabobo, Venezuela.

a Maestría en Biología Oral.

${ }^{\mathrm{b}}$ Magister en Desarrollo Curricular.

c Magister en Biología Oral.

\section{Correspondencia:}

Davide Mobili-Rocaro: dmobilirocaro@gmail.com Urb. Valle Verde, Manzana 9, Casa 5. San Diego, Estado Carabobo. Venezuela.

ORCID: 0000-0003-4713-8165

\section{Coautores:}

Omaira Fernández: omairaisabel24@gmail.com ORCID: 0000-0002-6799-9045

Patricia Rodríguez: patriciarodriguez497@gmail.com ORCID: 0000-0002-7562-9757

Miguel Flores-Asenso: miguelignacioflores@gmail.com ORCID: 0000-0003-3863-2487

María Cristina Aguilera: tinaveya@gmail.com ORCID: 0000-0002-9232-8286

Editora:

Antonieta Pérez-Flores

Universidad de Concepción, Chile.

Conflicto de intereses: los autores declaran no tener conflictos de interés.

Fuente de financiamiento: propio.

\section{Recibido: $23 / 03 / 20$}

Aceptado: $10 / 07 / 20$

Publicado: 04/08/20

(C) Los autores. Este artículo es publicado por la revista Odontología Sanmarquina de la Facultad de Odontología, Universidad Nacional Mayor de San Marcos. Este es un artículo de acceso abierto, distribuido bajo los términos de la licencia Creative Commons Atribucion - No Comercia_Compartir Igual 4.0 Internacional. (http://creativecommons.org/licenses/by-nc-sa/4.0/) que permite el uso no comercial, distribución y reproducción en cualquier medio, siempre que la obra original sea debidamente citada. 
dysbiosis to be analyzed, both orally and systemically. More studies are required to gain an in-depth understanding of this complex relationship and its impact on the health status of individuals.

Keywords: Microbiome; Microbiota; Oral cavity; Virome (source: MeSH NLM).

\section{Introducción}

La cavidad bucal, conforma el sistema estomatognático y constituye la primera porción del aparato digestivo, la componen estructuras diversas con funciones específicas, principalmente digestivas, fonéticas, funcionales y estéticas. Como toda cavidad corporal representa una puerta de entrada a agentes agresores, principalmente microorganismos patógenos que pretenden colonizar esta cavidad y diseminarse por toda la economía corporal ${ }^{1}$.

Sin embargo, el sistema inmunológico tiene diferentes mecanismos para evitar la colonización y diseminación de patógenos, como lo es la respuesta inmune innata, representada, entre otros mecanismos, por la presencia de lisozimas, barreras físicas, barreras fisiológicas, células fagocíticas y la microbiota habitual ${ }^{2}$. Esta última, se describe como una serie de microorganismos que conviven en una relación de comensalismo o mutualismo con el ser humano, tienen una baja virulencia y representan una de las primeras líneas de defensa del organismo ya que compiten con los patógenos exógenos por los nutrientes. Esta compleja diversidad de organismos que representan la microbiota bucal incluyen principalmente bacterias y hongos, su equilibrio depende de factores como la dieta, la higiene, el estado nutricional del huésped, entre otros ${ }^{3}$.

Por esta razón, el impacto que tiene la microbiota bucal con la salud y la enfermedad han motivado a la realización de estudios microbiológicos, inmunológicos y moleculares, los cuales han permitido conocer el genoma de todos los microorganismos que habitan en la cavidad bucal ${ }^{4,5,6}$, a este conjunto de genes microbianos tanto comensales como patógenos se le denomina microbioma ${ }^{7}$.

Por su parte, los virus han sido considerados patógenos verdaderos de la cavidad bucal, están representados por genoma, ADN o ARN con una estructura proteica denominada cápside, por carecer de metabolismo propio se les considera parásitos obligados ${ }^{8}$. La colección completa de genoma viral se le denomina viroma ${ }^{9,10,11}$.

En este sentido, existen muchos estudios que asocian al microbioma y el viroma bucal diferentes procesos de salud-enfermedad tanto a nivel bucal, como a nivel sistémico ${ }^{12}$. Su estudio y comprensión representan una de las vertientes más importantes de la Odontología y de las ciencias médicas en el futuro.

\section{Revisión de la literatura}

Microbiota y microbioma. La biota o microbiota define a una gran variedad de microorganismos que están en simbiosis con un huésped. Es así que el cuerpo humano alberga microbiota en las distintas zonas como la piel, cavidades y sistemas: óptico, digestivo, genito-urinario, respiratorio, estomatognático, en cada zona los microorganismos son diferentes y específicos en cantidad y diversidad ${ }^{13}$.

El concepto de microbioma tiene su origen en los esfuerzos realizados por Woese y Fox; Stahl et al; Woese y Olsen; Giovannoni et al.; Schmidt et al.; Dymock et al., para determinar el número de microbios en una comunidad y sus relaciones filogenéticas, para lo cual analizaron el $16 \mathrm{~S}$ relativamente bien conservado en genes de ARNr de microorganismos ${ }^{14}$.

El concepto del microbioma humano fue sugerido por primera vez por Joshua Lederberg, quien acuñó el término "microbioma", para significar la comunidad ecológica de microorganismos comensales, simbióticos y patógenos que comparten literalmente nuestro espacio corporal ${ }^{15}$, en este sentido el microbioma humano es un ecosistema interno constituido por el hombre y los microorganismos que en él conviven, microorganismos esenciales para mantener su salud, pues junto con el sistema inmunológico protegen frente a patógenos invasores y mantienen la salud, considerando que más de 10x13 microbios coexisten con las 10x12 células en el organismo humano ${ }^{16}$.

Tradicionalmente el fundamento de la microbiología era el cultivo de los microorganismos para identificarlos y diferenciarlos, sin embargo en la actualidad se implementa la metagenómica que permite identificar y diferenciar, a los microorganismos, mediante la biología molecular, donde el gold standard para la señalización e identificación es la subunidad $16 \mathrm{~S}$ del ARN ribosomal. La evolución de la técnica inicia con el método de Sanger o secuenciación de primera generación caracterizado por su sencillez y precisión, luego se desarrolló la segunda generación, o de alto rendimiento con la cual se producían, de forma rápida y a bajos costos, centenares de reacciones de secuencias, no obstante, es con la secuenciación de tercera generación, con el manejo de un gen de referencia y tecnología bioinformática para recopilar los datos, que se ha podido tener información sobre el microbioma humano, permitiendo detallar características taxonómicas y fisiológicas de los microorganismos, lo que ha implicado el poder explicar los procesos de disbiosis, salud y enfermedad ${ }^{17}$.

En función a esto, más que yuxtaponer o enfrentar conceptos, la idea es relacionarlos, ya que, efectivamente, la composición de las comunidades de microorganismos (microbiota) ha resultado ser sorprendentemente diversa y abundante, en diversas zonas ddistintose un mismo individuo, y varía entre individuos, en efecto, individuos de una misma comunidad pueden compartir tipos similares de bacterias en su saliva, pero en el ámbito intrabucal, se encuentran distintos microorganismos 
bacterianos de un diente a otro diente, de una cara a otra cara de la misma unidad dental, o zona anatómica y, determinantemente heterogénea y variada es la microbiota supragingival de la microbiota subgingival ${ }^{18}$.

Es así, como el metagenoma del microbioma humano podría contener 8 millones de genes codificantes de proteínas, es decir, 360 veces más que el genoma de los seres humanos, los últimos estudios indican que el microbioma ha evolucionado a la vez que las personas, ayudándolas a sobrevivir y mejorando sus funciones vitales, mientras que otros microorganismos, por el contrario, están vinculados a enfermedades ${ }^{19}$.

Por otra parte, se deben considerar aspectos genéticos, y factores como la dieta, edad, sexo y el ambiente en que interactúa el huésped, por consiguiente, cada individuo tiene su microbioma propio ${ }^{20.21}$, lo que le da aún más naturaleza particular y única.

El hecho de que el microbioma esté en un huésped que interactúa con un ecosistema, obligatoriamente hace que sea un genoma en constante interacción con el medio ambiente, por ello una alteración en la composición o funcionamiento del entorno, es decir una disbiosis, afecta directamente al microbioma, lo que puede producir alteraciones en la respuesta inmune y ocasionar enfermedades ${ }^{22}$. Este desequilibrio o disbiosis, puede ser inducido por modificaciones en la dieta, el consumo de fármacos, especialmente antibióticos, incluso cambios de temperatura, y como consecuencia desencadenar padecimientos tan diversos como la diabetes, el intestino irritable, la obesidad, la depresión, el autismo o enfermedades autoinmunes, es decir, que el microbioma representa una fuente de información sobre las condiciones de salud del huésped, e inclusive como terapia para tratarlas ${ }^{23}$.

Proyecto microbioma humano (buman microbiome project). En las últimas décadas han venido evolucionado los avances científicos relacionados con el estudio de enfermedades crónicas y los órganos donde éstas tienen su origen, lo cual ha llevado a considerar toda la realidad que constituye dicho sitio patológico; por lo que, producto de estas investigaciones, ha surgido la relación entre la presencia bacteriana y cómo ésta se corresponde con el proceso salud - enfermedad.

Es así, como a partir del año 2007 que el Instituto Nacional de Salud en Estados Unidos, se propuso formar el Proyecto Microbioma Humano (PMH), creado con el interés de caracterizar la microbiota de voluntarios sanos, para así impulsar la investigación genómica y clínica, además de analizar sus implicaciones bioéticas. El PMH tuvo como objetivo determinar los microbiomas de 242 sujetos humanos sanos de sitios que incluyen la cavidad bucal, la cavidad nasal, la piel, el tracto gastrointestinal y el tracto urogenital. Los datos obtenidos de la secuenciación se utilizaron para la asignación taxonómica y también están disponibles a través del buscador de datos del centro de análisis y coordinación de datos del PMH. Este estudio se ha estado realizando gracias a los protocolos de métodos de laboratorio y el procesamiento de secuencias, el análisis de $16 \mathrm{~S}$ rDNA, secuencias de genoma completo y perfiles del microbioma. Dichos estudios han proporcionado información sobre lo que constituye el microbiota normal de cada órgano o mucosa en el cuerpo, lo que permite una mejor comprensión de cómo afectan la salud humana, por lo que, a partir de abril del año 2016, más de 1,300 cepas de referencia aisladas del cuerpo humano fueron secuenciadas y los datos disponibles públicamente para los investigadores ${ }^{14,24}$.

El término microbioma, se ha llegado a utilizar en el mismo sentido que microbiota, algunos autores no establecen ninguna diferencia en ambos términos, no obstante, se hace necesario, aclarar el término y diferenciarlo de microbiota.

Base de datos de los microorganismos de la cavidad bucal (microbioma de la cavidad bucal). El propósito de esta base de datos es proporcionar a la comunidad científica información completa sobre las aproximadamente 700 especies bacterianas predominantes que habitan la cavidad bucal humana ${ }^{25}$. Esta base de datos de $16 \mathrm{~S}$ rDNA proporciona un esquema de denominación provisional para las especies o filotipos actualmente sin nombre. Así mismo vincula los datos de secuencia de 701 taxones bucales con información fenotípica, filogenética, clínica y bibliográfica. Se ha llegado a confirmar muchas especies bucales bien conocidas, por ejemplo, que incluyen especies Prevotella, Porphyromonas, Treponema, Tannerella, Fusobacterium y Streptococcus, así como quizás algunas especies menos conocidas, por ejemplo, filotipos de miembros de los filos SR1, GNO2 y TM7, Fretibacterium, Solobacterium y Abiotrophia y su vinculación con la salud bucal y la enfermedad ${ }^{26}$.

Es relevante destacar, entonces, que en la boca está representado un $25 \%$ del microbioma humano ${ }^{27} \mathrm{y}$ contiene un número diferente de nichos ecológicos, entre los cuales se encuentran dientes, surco gingival, lengua, mejillas, paladar duro y blando entre otros; todos ellos colonizados por microorganismos, que se suelen presentar como biopelículas bacterianas más que como células planctonicas ${ }^{28}$. De hecho, la microbiota bucal es uno de los microbiomas mejor caracterizados de los que colonizan el cuerpo humano ${ }^{29}$. En efecto, así lo propone la Base de Datos de los Microbios de la Cavidad Bucal, que menciona que hay aproximadamente 700 especies procariotas presentes en la cavidad bucal humana ${ }^{30}$. Sin embargo, en disbiosis, se produce una alteración de esta, evidentemente, en caso de caries se disminuye de $600 \mathrm{a}$ 160 especies, desapareciendo las especies más resistentes a los ácidos, las cuales podrían ser un factor protector en este proceso patológico ${ }^{31}$ o que el uso de probióticos contribuiría en la prevención o el tratamiento de la patología ${ }^{32}$.

En este sentido, se ha descrito, una nueva especie en la cavidad bucal, Streptococcus dentisani ubicada en las unidades dentales de individuos sin caries, efectivamente, origina bacteriocinas que lisan a las bacterias causantes de esta patología ${ }^{33}$. En el surco gingival y en el colón la 
microbiota es similar, alcanza $10 \times 12$ por mililitro, donde los anaerobios son el 99\% de la población bacteriana ${ }^{34}$.

Microbioma y salud bucal. En condiciones de simbiosis, las especies de Streptococcus suelen ser los primeros microorganismos pioneros en colonizar la cavidad bucal, particularmente, Streptococcus salivarius, cuyo nicho principal está en el dorso de la lengua y en la saliva, así mismo, el Streptococcus mitis en la mucosa bucal y Streptoccocus sanguinis en los dientes ${ }^{35}$.

El crecimiento y el metabolismo de estas especies pioneras cambian las condiciones ambientales locales, como el potencial redox local, el pH, la coagregación y la disponibilidad de nutrientes, lo que permite a los organismos más exigentes colonizar después de ellos ${ }^{36}$.

Con el tiempo, otras comunidades microbianas toman el control, incluyendo Prevotella melaninogenica, Fusobacterium nucleatum, Veillonella, Neisseria y Prevotellas no pigmentadas. Con el desarrollo de los dientes, se observa un aumento en la presencia de géneros como Leptotrichia y Campylobacter y junto con la colonización por especies adicionales como Prevotella denticola y miembros de los géneros Fusobacterium y Selenomonas ${ }^{37}$.

La erupción de los dientes crea un nuevo hábitat, el surco gingival, que se nutre del fluido crevicular gingival. Junto con la saliva, el fluido crevicular es crítico para el mantenimiento de la integridad de los surcos gingivales y contiene péptidos antimicrobianos, inmunoglobulinas y una gama de otras proteínas activas que le permiten influir en la ecología de la cavidad bucal. Además, también contiene nutrientes que apoyan la microbiota. Esta continua sucesión de microbios eventualmente se reemplaza con una homeostasis estable de comunidades microbianas que se conoce como la comunidad clímax en la que diferentes bacterias interactúan para establecer un ecosistema donde cada comunidad contribuye de alguna forma ${ }^{36}$.

Dependiendo del nicho ecológico bucal y de los individuos, se han identificado muchas especies asociadas al estado de salud de dicho tejidos, es por ello que, mediante el uso del enfoque $16 \mathrm{~S}$ rRNA, se ha establecido que en el dorso de la lengua, las partes laterales de la lengua, la mucosa bucal, el paladar duro y blando, la placa supragingival y subgingival, el vestíbulo anterior superior y las amígdalas, de individuos sanos, microbiota simbionte entre las que están los filotipos de Streptococcus, Granulicatella, Neisseria, Haemophilus, Corynebacterium, Rothia, Actinomyces, Prevotella, Capnocytophaga, Porphyromonas y Fusobacterium. Llegando a la conclusión de que la mayoría de los taxones bucales encontrados en individuos sanos no relacionados eran similares, y afirmando el concepto de un microbioma central sano ${ }^{38}$.

Microbioma y la caries dental. La caries dental es una enfermedad multifactorial, en ésta intervienen distintos factores como la dieta, la saliva, la anatomía de los dientes, la higiene bucal y, sin lugar a dudas la actividad de ciertos microorganismos. Como se ha descrito, la comunidad microbiana que habita en la cavidad bucal vive en equilibrio con el sujeto debido a diversos factores físicos, químicos e inmunológicos ${ }^{39,40}$.

En este sentido, la dieta rica en carbohidratos puede ocasionar una alteración en este equilibrio, generando de esta manera una disbiosis que se caracteriza por un incremento de bacterias acidogénicas y acidotolerantes ${ }^{41,42}$.

Dentro del grupo de microorganismos involucrados en esta disbiosis se encuentran Streptococcus mutans, Lactobacillus sp, Scardovia wiggsiae y Actinomyces spp. ${ }^{43}$.

Anteriormente, se asociaba la etiología de la caries dental casi exclusivamente a Streptococcus mutans, considerándose una enfermedad infecciosa atribuida a esta bacteria. Mientras que en la actualidad el nuevo paradigma enfatiza un enfoque mixto bacteriano-ecológico, los estudios recientes basados en Biología Molecular han detectado ADN y ARN en lesiones cariosas descubriendo un ecosistema muy amplio, diverso y complejo, en este S. mutans representa apenas una pequeña fracción de la comunidad bacteriana, en contraposición a la atribución que se le daba a este microorganismo en la etiología de la caries dental. Estos hallazgos sustentan la teoría de que los consorcios bacterianos actúan en conjunto y de manera sinérgica sobre los tejidos duros del diente ${ }^{44,45}$.

Microbioma y la enfermedad periodontal. La comprensión de la etiología de las enfermedades periodontales ha evolucionado conforme la ciencia ha avanzado, las nuevas tecnologías han permitido detectar ADN y ARN de diversos microorganismos en surcos gingivales y bolsas periodontales, determinando de esta manera que la comunidad microbiana y los conglomerados bacterianos son más complejos de lo que se pensaba anteriormente ${ }^{46,47}$.

Los periodontopatógenos clásicos incluyen Aggregatibacter actinomycetemcomitans, Porphyromonas gingivalis, Peptostreptococcus anaerobius, algunas Prevotellas y Treponemas. Sin embargo, los análisis del microbioma de algunos sujetos con enfermedad periodontal han revelado la aparición de 3 géneros/especies que podrían ser considerados como nuevos patógenos periodontales debido a su elevada frecuencia de aparición en varios estudios donde se empleó biología molecular, estos microorganismos fueron: Desulfobulbus spp, Filifactor alocis y TM7 spp. Un punto importante de resaltar es que Desulfobulbus spp, y TMT spp han sido detectados con la misma frecuencia que otros patógenos periodontales conocidos, además Filifactor alocis ha sido detectado en algunas oportunidades con mayor frecuencia que Porphyromonas gingivalis y Treponema denticola. De igual forma, han sido encontrados Proteobacterias, Clamydias, Flavobacterias, Coriobacteria, Bifidobacteriales y varios filotipos del orden Clostridiale, al igual que Enterobacterias, Staphylococcus y otras bacterias poco comunes de asociarse a la enfermedad periodontal ${ }^{48}$.

Estos nuevos descubrimientos permiten tener una mejor comprensión de la etiología diversa y compleja de la enfermedad periodontal, en la cual se han sumado numerosos microorganismos que, si bien no se conoce el papel que juegan en la aparición y evolución de esta 
enfermedad, su presencia debe tomarse en cuenta para futuras investigaciones ${ }^{48}$.

Papel del microbioma bucal en la diabetes mellitus. Algunas enfermedades endocrinas como la diabetes mellitus han sido estudiadas en diversas oportunidades en cuanto a su relación con el papel del microbioma. Con respecto a la cavidad bucal, se han encontrado diferencias significativas entre la microbiota subgingival de pacientes diabéticos y pacientes no diabéticos, algunos hallazgos de estos estudios han demostrado un mayor porcentaje de TM7, Aggregatibacter, Neisseria, Gemella, Eikenella, Selenomonas, Capnocytophaga, Fusobacterium, Veillonella y Streptococcus ${ }^{48}$.

Además, se ha descrito como la diabetes ocasiona un cambio en la composición bacteriana de la cavidad bucal, algunos estudios realizados con biomodelos animales han encontrado que la microbiota bucal de ratones diabéticos es más patógena que los animales sanos. De igual forma, el tratamiento con anticuerpo IL-17 reduce la patogenicidad de la microbiota bucal en ratones diabéticos, y cuando se realizó la transferencia a animales libres de gérmenes, la microbiota bucal de los donantes tratados con IL-17 indujo un reclutamiento reducido de neutrófilos, además de reducir la IL-6 y RANKL, ocasionó una menor reabsorción ósea. Por lo que la IL17 que se usó en ratones diabéticos altera la microbiota bucal y la hace más patógena ${ }^{48}$.

Microbioma bucal y las enfermedades cardiovasculares. Las enfermedades cardiovasculares se han asociado a la periodontitis, debido a la inflamación sistémica, el microbioma bucal juega un papel importante en la aparición de placas de ateroma, relacionándose de esta manera la cantidad y diversidad de microorganismos con la aterogénesis ${ }^{48}$. Estos microorganismos asociados con la enfermedad periodontal generan productos como las endotoxinas que tienen acceso a la circulación sanguínea mediante los tejidos bucales e incluso la saliva, ocasionando respuestas inflamatorias a nivel sistémico. Estudios inmunológicos y moleculares afirman que la disbiosis bucal es un factor de riesgo cardiovascular ${ }^{46}$, como la aparición de aterosclerosis subclínica, enfermedad coronaria e incluso accidente cerebrovascular. Además de los anticuerpos específicos de la especie bacteriana, la respuesta inmunológica incluye anticuerpos proaterogénicos persistentes, con reacción cruzada, contra antígenos derivados del humano. A su vez, las lipoproteínas responsables de la formación de las placas de ateroma se ven afectadas por los productos tóxicos que son liberados a la sangre desde la cavidad bucal ${ }^{48}$.

El lipopolisacárido (LPS) es una endotoxina y un importante factor de virulencia de las bacterias gramnegativas, algunas de las especies asociadas con la periodontitis, como Porphyromonas gingivalis, pueden invadir y replicar en las células epiteliales. Se ha demostrado que la exposición bucal de $P$. gingivalis altera la composición de la microbiota intestinal aumentando las proporciones del filo Bacteroidetes a expensas del filo Firmicutes con un aumento concomitante en la actividad de la endotoxina sérica ${ }^{48}$. Por lo tanto, el LPS se considera un enlace molecular entre el microbioma y los trastornos cardiometabólicos, por ejemplo, se ha demostrado que el LPS salival se correlaciona con la actividad del LPS en suero, y esta asociación mejoró cuando estaba presente la enfermedad periodontal ${ }^{48}$.

Viroma humano. El viroma humano se refiere al conjunto de todos los virus que habitan en el organismo humano, incluyendo los virus causantes de infecciones agudas, persistentes y latentes. Los virus son considerados microorganismos intracelulares estrictos por lo tanto mantienen una relación estrecha con su huésped que muchas veces va más allá de infectar una célula del mismo y causar una determinada patología ya que además pueden desarrollar una simbiosis con el organismo huésped y contribuir a que exista un equilibrio en el mismo, resultando en un efecto beneficioso ${ }^{49}$.

El viroma humano está conformado por virus que infectan las células humanas, derivados antiguos de virus que se han insertado en los cromosomas de las células del huésped y bacteriófagos que infectan a una gran cantidad de bacterias ${ }^{50}$. La acción de estos últimos ha sido objeto de estudio debido a que invaden el ADN de la célula bacteriana e inducen procesos de lisis o destrucción celular, pudiendo esto marcar un nuevo precedente en la terapéutica de procesos infecciosos a nivel bucal y sistémico. Además, se ha comprobado que existen interacciones entre el viroma y las bacterias y demás microorganismos que habitan en el huésped, incluso las características y composición del viroma pudieran influir y a su vez modificar la microbiota específica de determinadas regiones ${ }^{51}$.

Viroma y microbioma humano. El organismo humano está compuesto por aproximadamente 10 billones de células y existe alrededor del doble o más de microorganismos presentes en todo el organismo, con diferencias notorias en los distintos sitios (tejidos, órganos o sistemas); de manera que el cuerpo humano sirve de hábitat para millones de microorganismos dentro de los cuales existen bacterias, hongos y virus ${ }^{52}$. Todos ellos mantienen una relación de simbiosis con su huésped, por lo tanto, no todos resultan perjudiciales o patógenos, por el contrario muchos de éstos son los responsables del mantenimiento de la homeostasis de los sistemas, son necesarios para procesos metabólicos y defienden al huésped de procesos infecciosos ya que son capaces de interactuar con agentes patógenos extrańos y neutralizarlos. El viroma está constituido por virus que habitan en las células del ser humano, fragmentos de virus antiguos que se integran al ADN celular y bacteriófagos (Fagos) que son virus que invaden la célula bacteriana, específicamente su genoma e inducen lisis y destrucción celular ${ }^{53}$.

Por lo tanto, se puede afirmar que, así como hay virus con efecto beneficioso para el organismo y el mantenimiento de la simbiosis, existen infinidad de virus oportunistas que se pueden incorporar al viroma de un individuo y están relacionados con cientos de enfermedades; un descubrimiento relativamente reciente son los oncovirus3 los cuales se encuentran en relación con distinto 
tipos de cáncer. De acuerdo a su más reciente estimación en el año 2012, la agencia internacional de investigación para el cáncer determinó que de un total de 200000 nuevos casos de carcinoma bucal, la fracción atribuible a oncovirus se estima en un 4,3\%, pero sólo el virus papiloma humano (VPH), principalmente los tipos 16 y 18 han sido identificados como factor de riesgo en la cavidad bucal, los cuales son comúnmente detectados a través de la amplificación de PCR de los genes que codifican las proteínas E6/E7 ${ }^{54}$.

La relación del genoma humano con los virus es mucho más profunda de lo que se cree ya que ambos han ido de la mano en la evolución genómica y de hecho esta relación se remonta al proceso de composición del $\mathrm{ADN}$ de todos los mamíferos, mucho antes de la separación de los grupos; los genomas de los mamíferos contienen en promedio $40 \%$ de productos de transcripción inversa los cuales ensamblan la integración de provirus antiguos; la infección por retrovirus exógeno puede resultar de la integración del genoma viral dentro del genoma del huésped; de hecho muchas de estas inserciones se estima que han ocurrido hace algunos 40 a 90 millones de años ${ }^{53}$

Estas secuencias de transcripción reversa se caracterizan por tener largas secuencias terminales repetitivas, y se conocen como retrovirus endógenos (ERVs) y se estima que representan del 8 al 10\% de todo el ADN humano y de ratón. La capacidad que tienen de ser reversibles ha sido ampliamente estudiada y el papel patógeno que tienen está relacionado a un efecto global mutagénico de retro-transcripción de elementos móviles del genoma lo cual puede causar disrupción genética ${ }^{55}$.

Viroma bucal. En la cavidad bucal los virus son los microorganismos más abundantes en el microbioma bucal ${ }^{53}$, sin embargo, son poco los estudios referidos acerca de su biodiversidad y su importancia en los procesos de salud y enfermedad ${ }^{53}$.

Es importante comprender en profundidad los virus que habitan en la cavidad bucal, para ello un estudio examinó la saliva de ocho individuos no relacionados entre sí por un período de 60 días, de forma que se pudiera caracterizar las diferencias longitudinales en los virus bucales humanos, el objetivo principal del estudio consistió en determinar si los virus bucales eran específicos en cada persona y si los genotipos virales persistían a lo largo del tiempo, se encontró un subconjunto de genotipos virales homólogos en todos los individuos lo que plantea que estos virus son habituales en personas sanas, por otro lado se encontraron genotipos virales propios de cada individuo, lo que indica que los virus son una característica altamente personalizada del microbioma bucal, también se encontró asociación con el sexo ya que la comunidad viral tenían características similares en cada género, entre las conclusiones del estudio señalan que los virus tienen un papel fundamental en el ecosistema bucal humano ya que muchos de éstos son estables y miembros específicos de cada individuo en su microbioma bucal ${ }^{55}$.
Viroma y lesiones en la cavidad bucal. En este contexto, estudios señalan que el viroma bucal podría estar asociado con enfermedades bucales como la leucoplasia verrugosa proliferativa (LVP) que es una forma maligna de leucoplasia bucal (LO) que con el tiempo las LVP derivan en un tipo de cáncer bucal agresivo como el carcinoma de células escamosas (COCE) ${ }^{56}$. Las manifestaciones bucales de la LO se presentan como lesiones blanquecinas hiperqueratóticas, se ha descartado que éstas estén relacionadas al consumo de alcohol y al hábito del tabaco por lo tanto hasta la fecha se desconoce el agente etiológico ${ }^{56}$.

Es por ello que estudios recientes están enfocados a relacionar estas lesiones con un agente de origen vírico, debido a la alta tasa de recurrencia de la lesión y su mulifocalidad. Para poder determinar el posible agente causal los autores señalan que han desarrollado estudios con biopsias de pacientes diagnosticados con LVP, LO y COCE con el fin de indagar la presencia de virus oncogénicos como Herpesvirus, Epstein-Barr, Polvomavirus y Papilomavirus utilizando la reacción en cadena de la polimerasa (PCR) el análisis profundo de este estudio concluye que no se obtuvo información estadísticamente significativa que permita determinar algún virus de la fracción de $\mathrm{ADN}$ o ARN como agente etiológico de las lesiones o el carcinoma de células escamosas en la cavidad bucal, la conclusión del estudio señala que no se ha podido encontrar un agente causal para la LVP ${ }^{54}$.

Dentro de las lesiones bucales que con mayor frecuencia se encuentran hay que mencionar las causadas por VPH, debido a que es una de las infecciones virales más diseminadas a nivel mundial ${ }^{55}$. Se han identificado más de 75 genotipos de VPH y se han clasificado según su riesgo de malignidad; de ellos, los genotipos 13 y 32 son exclusivos de cavidad bucal. El papiloma virus presenta un alto tropismo por las células epiteliales, invade la célula con mayor frecuencia de las capas basales del epitelio e induce la formación de lesiones hiperplásicas como vegetaciones, verrugosidades y papilomas que por lo general suelen ser benignos. Tiene predilección por tejidos que presentan alta tasa de proliferación, por lo tanto, el virus se replica con la célula. Los subtipos 6 y 11 están relacionados a papiloma bucal ${ }^{42}$ y son frecuentemente hallados en cavidad bucal. En muchos casos el sistema inmunológico logra contrarrestar el virus, sólo en aquellos donde la respuesta inmune es insuficiente se manifiesta clínicamente. En ocasiones se identifica la presencia del virus integrado a las células sin manifestación clínica ${ }^{54}$.

Viroma y enfermedad periodontal. En este orden de ideas, otro estudio realizó la toma de muestra de saliva y biopelículas subgingivales y supragingivales en individuos sanos y con enfermedad periodontal de forma que pudiese identificarse si existen diferencias en las comunidades virales y su relación al estado de salud bucal, los resultados revelaron diferencias en la composición del viroma en individuos sanos periodontalmente y en pacientes con enfermedad periodontal, en estos últimos la ecología viral se encontraba alterada lo que sugiere 
que la composición del viroma están asociadas significativamente al estado de salud bucal ${ }^{55}$. Se tomaron las muestras de saliva, placa subgingival y supragingival de dieciséis personas, siete de éstos tenían enfermedad periodontal, mientras que los otros nueve tuvieron una buena salud periodontal general. El análisis de los resultados se realizó a través de un análisis de coordenadas principales (PCOA) para comparar los patrones. Los viromas subgingivales y supragingivales en pacientes con enfermedad periodontal se agruparon de manera similar, indicando que el viroma bucal está asociado a la salud bucal ${ }^{56}$.

También se identificó la presencia abundante de Myovirus en pacientes con enfermedad periodontal, por otro lado, en los individuos sanos el tipo viral más común fue Siphovirus. Los Mycovirus son altamente líticos y su predominio en la enfermedad periodontal sugiere un papel activo de éstos en la conducción de la diversidad bacteriana en la placa subgingival ${ }^{56}$.

Terapia fágica como alternativa terapeútica ante procesos infecciosos. Los bacteriófagos o fagos son virus, que invaden la célula bacteriana, específicamente su genoma e inducen lisis y destrucción celular ${ }^{53}$; se ha demostrado que representan la población más abundante del viroma oral.

El descubrimiento y posterior identificación de la estructura molecular de los fagos al microscopio electrónico, llamó la atención por el efecto beneficioso que tienen al eliminar células bacterianas y por lo tanto lo consideraron como una potencial opción terapéutica en enfermedades infecciosas, de esta manera nació la terapia fágica ${ }^{57}$. Hay evidencias de mejoría en patologías al inyectar una única dosis de fagos. Éstos últimos son reconocidos a través de técnicas de biología molecular; desde un punto de vista clínico, los fagos resultaron inocuos cuando fueron administrados en vía bucal en pastillas o jarabes en una dosis de 10x 5 o 10x11 UFP (unidades formadoras de placa), lo cual era de esperarse debido a que forman parte del viroma humano que coloniza los órganos y sistemas, además están presentes en una gran concentración en el medio ambiente (agua de mar) y son consumidos en diversidad de alimentos. Sin embargo, existía mucho desconocimiento sobre esta terapia, sobre todo en aspectos biológicos sobre los fagos y datos farmacocinéticos acerca de su eliminación del torrente sanguíneo, todo ello sumado a la llegada de la era de los antibióticos hizo que la terapia fágica quedara en desuso por varias décadas ${ }^{57}$.

Al tiempo que surgió la gran ola de resistencia microbiana ante la terapia antibiótica y con la subsecuente problemática, resurgió la terapia fágica como alternativa terapéutica ante infecciones bacterianas resistentes a antibióticos ${ }^{57}$. Se puede decir que dicha terapia constituye una opción que se ha venido implementando en Europa occidental desde la década de los 40 y la cuál combate enfermedades infecciosas mediante la incorporación de fagos al organismo, los cuales restablecen el equilibrio eliminando las células bacterianas ${ }^{57}$.
En la actualidad, se ha reportado de esta terapia en el control biológico de E. coli, la cual produce colitis hemorrágica; así mismo también se ha empleado sobre enterococos nosocomiales. No obstante la terapia con fagos presentó algunas limitantes, una de las más notorias es la neutralización de los fagos por parte del sistema retículo endotelial del huésped; para lo cual se lograron crear fagos mutantes que presentaban una pequeña variación en la Proteína E de la cápside, que consistía en una sustitución de un residuo de Acido glutámico por uno de lisina, y con ello se producía un cambio conformacional de la estructura tridimensional de la proteína E que lograba evadir el sistema retículo endotelial, es importante resaltar que el organismo cuenta con fagos intrínsecos que forman parte del viroma, los cuales se encuentran en constante interacción con los demás microorganismos comensales que habitan en cada uno de los sistemas y son partícipes activos en el mantenimiento de la simbiosis en el proceso salud-enfermedad ${ }^{57}$.

En este sentido, los primeros estudios de fagos en la cavidad bucal se basaron en la presencia de partículas similares a virus, a través de muestras de la placa dental identificándolos utilizando microscopía electrónica, microscopía de epiflorescencia y secuenciación metagenómica para demostrar la diversidad de fagos bucales, gracias a estos avances en la investigación se puede reconocer que la cavidad bucal alberga una gran población de virus como circovirus, herpesvirus, Epstein Barr entre otros, siendo los fagos los más abundantes, sin embargo son pocos los estudios que hayan demostrado la presencia de fagos en las zonas supragingivales, subgingivales y en la placa dental ${ }^{58}$.

\section{Conclusiones}

La cavidad bucal se encuentra ampliamente habitada por virus y bacterias que conforman la microbiota bucal, siendo uno de los microbiomas mejor descritos. El rol de varias de las comunidades microbianas (microbioma) ha sido identificado, sin embargo, el papel que desempeña el viroma, no presenta suficiente evidencia científica, por lo que investigaciones recientes se han enfocado en identificar la importancia de su presencia en la cavidad bucal; los resultados revelan que son importantes para la configuración de la ecología de las bacterias bucales, aceleración de la diversidad molecular y protección del huésped de otros patógenos. Mediante técnicas metagenómicas se sugiere una función protectora a través de simbiosis o sinergia entre virus y bacterias, su alteración puede ocasionar disbiosis, por lo cual esta evidencia podría servir como una potencial opción terapéutica para evitar la colonización y agregación de microorganismos que con lleven procesos patológicos en la cavidad bucal y a nivel sistémico, procesos que ameritan investigaciones sustentadas en sólidas bases científicas.

\section{Referencias bibliográficas}

1. Angarita-Díaz MP. Probióticos y su relación con el control de caries. Revisión de tema. Rev Fac Odontol Univ Antioq. 2016;28(1):179-202. 
2. Ballón-Salcedo C, Cacya-Apaza I, Valdivia-Silva J. Inmunidad de la mucosa oral: nuevas tendencias en investigación. Dermatol Peru. 2019;29(1):22-30.

3. Pascale A, Marchesi N, Marelli C, et al. Microbiota and metabolic diseases. Endocrine. 2018;61(3):357-71.

4. Caselli E, Fabbri C, D'Accolti M, et al. Defining the oral microbiome by whole-genome sequencing and resistome analysis: the complexity of the healthy picture. BMC Microbiol. 2020;20(1):120. Published 2020 May 18. DOI:10.1186/s12866-020-01801-y

5. Balachandran $M$, Cross K, Podar M. Single-Cell Genomics and the Oral Microbiome. J Dent Res. 2020;99(6):613-20.

6. Zhang Y, Wang X, Li H, Ni C, Du Z, Yan F. Human oral microbiota and its modulation for oral health. Biomed Pharmacother. 2018;99:883-93.

7. Mark Welch J, Dewhirst F, Borisy G. Biogeography of the Oral Microbiome: The Site-Specialist Hypothesis. Annu Rev Microbiol. 2019;73:335-58.

8. González A, Gonzáles D, Drusso G. Diagnóstico y tratamiento de un papiloma solitario de lengua. Reporte de un caso y revisión de la literatura. Rev Odontol Mex. 2016;(20)1:39-43.

9. Freer G, Maggi F, Pifferi M, Di Cicco M, Peroni D, Pistello M. The Virome and Its Major Component, Anellovirus, a Convoluted System Molding Human Immune Defenses and Possibly Affecting the Development of Asthma and Respiratory Diseases in Childhood. Front Microbiol. 2018;9,686.

10. Abbas A, Diamond J, Chehoud C, Chang B, Kotzin JJ, Young JC, et al. The perioperative lung transplant virome: torque teno viruses are elevated in donor lungs and show divergent dynamics in primary graft dysfunction. Am. J. Transplant. 2017;17(5):1313-24.

11. Añé A. The human virome. Its implications in health and disease. Revista Habanera de Ciencias Médicas. 2018;17(3):376-85.

12. Michel A, Izeta G, Torres A, et al. La microbiota y el microbioma intestinal humano (Entre las llaves del reino y una nueva caja de Pandora). Rev Sanid Milit Mex. 2017;71(5):443-8.

13. Lloyd-Price J, Abu-Ali G, Huttenhower C. The healthy human microbiome. Genome Med. 2016;(8):51.

14. Peterson J, Garges S, et al. The NIH Human Microbiome Project. Genome Res. 2009;19(12):2317-23.

15. Prussin A, Marr L. Sources of airborne microorganisms in the built environment. Microbiome. 2015;3:78

16. Man W, de Steenhuijsen P, Bogaert D. The microbiota of the respiratory tract: gatekeeper to respiratory health. Nat Rev Microbiol. 2017;15:259-70

17. Suárez A. Microbioma y secuenciación masiva. Rev Esp Quimioter. 2017;30(5):305-11.

18. Lafaurie G, Sabogal M, Castillo D, et al. Microbiome and Microbial Biofilm Profiles of Peri-Implantitis: A Systematic Review. J Periodontol. 2017;88(10):1066-89.

19. Lloyd-Price J, Mahurkar A, Rahnavard G, et al. Strains, functions and dynamics in the expanded Human
Microbiome Project [published correction appears in Nature. 2017 Oct 12]. Nature. 2017;550(7674):61-6.

20. Ariza-Andraca R, García-Ronquillo M. El microbioma humano. Su papel en la salud y en algunas enfermedades. Cirugía y Cirujanos. 2016;84:31-5.

21. Conlon M, Bird A. The impact of diet and lifestyle on gut microbiota and human health. Nutrients. 2015;7(1):17-44.

22. Scott A, Alexander J, Merrifield C, et al. International Cancer Microbiome Consortium consensus statement on the role of the human microbiome in carcinogenesis. Gut. 2019;68(9):1624-32.

23. Pulikkan J, Mazumder A, Grace T. Role of the Gut Microbiome in Autism Spectrum Disorders. Adv Exp Med Biol. 2019;1118:253-69.

24. Krishnan K, Chen T, Paster B. A practical guide to the oral microbiome and its relation to health and disease. Oral Dis. 2017;23(3):276-86

25. Deo P, Deshmukh R. Microbioma oral: desvelando los fundamentos. J Oral Maxillofac Pathol. 2019;23(1):122-28.

26. Benn A, Heng N, Broadbent J, Thomson W. Studying the human oral microbiome: challenges and the evolution of solutions. Aust Dent J. 2018;63(1):14-24.

27. Baker J, Bor B, Agnello M, Shi W, He X. Ecology of the Oral Microbiome: Beyond Bacteria. Trends Microbiol. 2017;25(5):362-74.

28. Costalonga M, Herzberg M. The oral microbiome and the immunobiology of periodontal disease and caries. Immunol Lett. 2014;162(2 Pt A):22-38

29. Solbiati J, Frias-Lopez J. Metatranscriptome of the Oral Microbiome in Health and Disease. J Dent Res. 2018;97(5):492-500.

30. Verma D, Garg PK, Dubey AK. Insights into the human oral microbiome. Arch Microbiol. 2018;200(4):525-40.

31. Tanner ACR, Kressirer CA, Rothmiller S, Johansson I, Chalmers NI. The Caries Microbiome: Implications for Reversing Dysbiosis. Adv Dent Res. 2018;29(1):78-85.

32. Rosier BT, Marsh PD, Mira A. Resilience of the Oral Microbiota in Health: Mechanisms That Prevent Dysbiosis. J Dent Res. 2018;97(4):371-80.

33. López-López A, Camelo-Castillo A, Ferrer MD, Simon-Soro Á, Mira A. Health-Associated Niche Inhabitants as Oral Probiotics: The Case of Streptococcus dentisani. Front Microbiol. 2017;8:379.

34. Le Bars P, Matamoros S, Montassier E, et al. The oral cavity microbiota: between health, oral disease, and cancers of the aerodigestive tract. Can J Microbiol. 2017;63(6):475-92.

35. Philip N, Suneja B, Walsh L. Beyond Streptococcus mutans: clinical implications of the evolving dental caries aetiological paradigms and its associated microbiome. $\mathrm{Br}$ Dent J. 2018;224(4):219-25.

36. García S, Blackledge M, Michalek S, Su L, Ptacek T, Eipers P, et al. Targeting of Streptococcus mutans Biofilms by a Novel Small Molecule Prevents Dental Caries and Preserves the Oral Microbiome. J Dent Res. 2017;96(7):807-14. 
37. Dzidic M, Collado M, Abrahamsson T, Artacho A, Stensson M, Jenmalm MC, et al. Oral microbiome development during childhood: an ecological succession influenced by postnatal factors and associated with tooth decay. ISME J. 2018;12(9):2292-306.

38. Yamashita Y, Takeshita T. The oral microbiome and human health. J Oral Sci. 2017;59(2):201-06.

39. Jiang Q, Liu J, Chen L, Gan N, Yang D. The Oral Microbiome in the Elderly With Dental Caries and Health. Front Cell Infect Microbiol. 2019;8:442.

40. Seerangaiyan K, van Winkelhoff AJ, Harmsen HJM, Rossen JWA, Winkel EG. The tongue microbiome in healthy subjects and patients with intra-oral halitosis. J Breath Res. 2017;11(3):036010.

41. Simón-Soro A, Mira A. Solving the etiology of dental caries. Trends in Microbiology. 2015;23(2):76-82.

42. Rutter-Locher Z, Fuggle N, Orlandi M, et al. Periodontal disease and autoimmunity: what we have learned from microbiome in rheumatology. J Intech. 2017;(6):127-9.

43. Ganji K, Tantry B. Prevalence and Molecular Analysis of Novel Newly Identified Periodontal Pathogens in Subgingival Plaque Samples of Saudi Patients with Chronic Periodontitis. Pesqui. Bras. Odontopediatria Clín Integr. 2019;19:e4679.

44. Kilian M, Chapple ILC, Hannig M, Marsh P D, Meuric $\mathrm{V}$, Pedersen A M L, et al. The bucal microbiome-an update for bucal healthcare professionals. British Dental Journal, 2016;221(10):657.

45. Cherkasov SV, Popova LY, Vivtanenko TV, et al. Bucal microbiomes in children with asthma and dental caries. Bucal Dis. 2019;25(1):898-910.

46. Kinane DF, Stathopoulou PG, Papapanou PN. Periodontal diseases. Nat Rev Dis Primers. 2017;3:17038.

47. Lundmark A, Hu YOO, Huss M, Johannsen G, Andersson AF, Yucel-Lindberg T. Identification of Salivary Microbiota and Its Association with Host Inflammatory Mediators in Periodontitis. Front Cell Infect Microbiol. 2019;9:216.
48. Gao L, Xu T, Huang G. et al. Bucal microbiomes: more and more importance in bucal cavity and whole body. Protein Cell. 2018;9(1):488-500.

49. Zárate S, Taboada B, Yocupicio-Monroy M, Arias CF. Human Virome. Arch Med Res. 2017;48(8):701-16.

50. Moreno-Gallego JL, Chou SP, Di Rienzi SC, et al. Virome diversity correlates whith intestinal microbiome diversity in adult monozgotic twins. Cell host microbe. 2019;25(2):261-72.e5

51. Stern J, MillerG, Li X, Saxena D. Virome and bacteriome: two sides of the same coin. Curr Opin Virol. 2019;37:37-43.

52. Milani C, Duranti S, Bottacini F, et al. The first microbial colonizers of the human gut: composition, activities, and helth implications of the infant gut Microbiota. Microbiol Mol Bio Rev. 2017;81(4):e00036-17.

53. Carroll D, Daszak P, Wolfe Nd, et al. The global virome Project. Sciencie. 2018;359(6378):872-4.

54. Valls-Ontañón A, Hernández-Losa J, Somoza R, et al. Impacto f human papiloma virus in patients with oral and oropharyngeal squamous cell carcinomas. Med clin. 2019;152(5):174-80.

55. Guerrero-Latorre L, Romero B, Bonifaz E, Timoneda N, Rusinol M, et al. 2018. Quito's virome: metagenomic analysis of viral diversity in urban streams of Ecuador's capital city. Sci. Total Environ. 2018;645:1334-43.

56. Mira A, Simon-Soro A, Curtis M. Role of microbial communities in the pathogenesis of periodontal diseases and caries. J Clin Periodontol. 2017;44(18):23-38.

57. Edlund A, Santiago-Rodriguez TM, Boehm TK, Pride DT. Bacteriophage and their potential roles in the human oral cavity. J Oral Microbiol. 2015;7:27423.

58. Milavetz B, Balakrishnan L. Viral epigenetics. Meth Mol Biol. 2015;1238:569-96. 
